\title{
Clinical Implications of Age in Differentiated Thyroid Cancer: Comparison of Clinical Outcomes between Children and Young Adults
}

\author{
Kwangsoon Kim $\mathbb{D}^{1},{ }^{1}$ Sang-Wook Kang, Jandee Lee, ${ }^{2}$ Jong Ju Jeong $\mathbb{D}^{2},{ }^{2}$ \\ Kee-Hyun Nam $\mathbb{D}^{2}$, and Woong Youn Chung ${ }^{2}$ \\ ${ }^{1}$ Department of Surgery, College of Medicine, The Catholic University of Korea, Seoul, Republic of Korea \\ ${ }^{2}$ Department of Surgery, Yonsei University College of Medicine, Seoul, Republic of Korea \\ Correspondence should be addressed to Kwangsoon Kim; noar99@naver.com and Jong Ju Jeong; jungjongj@yuhs.ac
}

Received 21 December 2021; Accepted 27 January 2022; Published 21 February 2022

Academic Editor: Alessandro Galani

Copyright (c) 2022 Kwangsoon Kim et al. This is an open access article distributed under the Creative Commons Attribution License, which permits unrestricted use, distribution, and reproduction in any medium, provided the original work is properly cited.

\begin{abstract}
Background. Pediatric patients with differentiated thyroid cancer (DTC) present with unique characteristics compared to adult patients. This study aimed to evaluate clinical presentation and surgical outcomes according to age and to identify the clinical significance of age in DTC. Methods. In total, 98 pediatric patients, 1261 young adult patients, and 4017 adult patients with DTC who underwent thyroid surgery between January 1982 and December 2012 at Yonsei University Hospital (Seoul, Republic of Korea) were retrospectively reviewed. The mean follow-up duration was $120.4 \pm 54.2$ months. Results. Mean tumor size was significantly larger in the pediatric group than in the adult groups $(p<0.001)$. The recurrence rate was significantly higher in the pediatric group ( $14.3 \%$ versus $6.6 \%$ versus $3.0 \%, p=0.004$ and $p<0.001)$. In multivariate analysis, the risk of disease-free survival (DFS) was lower in the adult group (HR, $0.362 ; p<0.001$ ). Reanalysis of patients with tumor size of $2-4 \mathrm{~cm}$ revealed that the adult group was not a significant risk factor for DFS in multivariate analysis (HR, $0.305 ; 95 \%$ CI, 0.158 to $0.588 ; p<0.001)$. Conclusions. Our findings suggest that pediatric patients present with more aggressive features and higher recurrence rates compared to adult patients and should be carefully treated from initial evaluation to surgery and postoperative care.
\end{abstract}

\section{Introduction}

Thyroid cancer is the most common endocrine malignancy, and its global incidence has increased over the past two decades [1-4]. The general use of high-resolution ultrasonography has increased the identification of small nodules, which may be undetected by physical examination. Thyroid cancer during childhood is rare and accounts for $1.5 \%$ to $3.0 \%$ of all childhood cancers, but reports indicate that this incidence is increasing $[2,5,6]$. Papillary thyroid cancer (PTC) is the most common thyroid cancer in both pediatric and adult patients. Follicular thyroid cancer (FTC) is the second most common thyroid cancer but is rare during childhood $[7,8]$.

Pediatric patients with differentiated thyroid cancer (DTC) present with several unique characteristics compared to adult patients. Compared to adult DTC, pediatric DTC tends to manifest as a more advanced disease at the time of diagnosis and is characterized by a more common extrathyroidal extension (ETE), lymph node metastasis, distant metastasis, and a higher risk of recurrence. Nevertheless, long-term prognosis has been reported to be better in pediatric patients than in adult patients [9-11].

Treatment of both pediatric and adult DTC comprises surgery, radioactive iodine (RAI) therapy, and thyroidstimulating hormone (TSH) suppression therapy. According to the American Thyroid Association (ATA) management guidelines for children with DTC, the surgery of choice in pediatric DTC is total thyroidectomy (TT), which is preferred due to the more aggressive features of pediatric DTC, such as ETE and bilateral or multifocal disease [12]. 
The incidence of pediatric DTC increases with age and is more predominant in females. Most of the patients are diagnosed in adolescence, and adolescents between 15 and 19 years of age have a 10-fold higher incidence compared to the younger population $[3,13,14]$. Nevertheless, the differences in clinical presentation and clinical outcomes between pediatric and adult patients with DTC remain unclear. This retrospective study therefore aimed to evaluate the clinical presentation and surgical outcomes of patients with DTC according to age and to identify the clinical significance of age in patients with DTC. Our findings indicated that pediatric patients with DTC tended to exhibit a more aggressive clinical presentation. Further, we identified age as an independent risk factor for disease-free survival (DFS), underscoring the need to ensure careful and appropriate treatment of pediatric patients with DTC.

\section{Materials and Methods}

2.1. Patients. In total, 110 pediatric ( $<20$ years old) patients, 1338 young adult patients (20-29 years old), and 4243 adult patients (30-39 years old) with DTC who underwent thyroid surgery at Yonsei University Hospital (Seoul, Republic of Korea) from January 1982 to December 2012 were retrospectively reviewed. In total, 12 pediatric patients, 77 young adults, and 226 adults were excluded owing to loss at followup and/or inadequate follow-up data. Baseline clinicopathological characteristics of study patients are presented in Table S1. All patients were analyzed by a complete review of medical charts and pathology reports. Of patients, 2620 (48.7\%) underwent lobectomy and/or contralateral partial thyroidectomy (less than TT) with prophylactic or therapeutic ipsilateral central compartment neck dissection (CCND) and 2756 (51.3\%) underwent TT with prophylactic or therapeutic ipsilateral CCND. Of patients who underwent TT, 691 (12.9\%) underwent TT with therapeutic modified radical neck dissection ( $\mathrm{mRND}$ ) due to clinically suspicious or pathologically confirmed N1b nodes. The mean follow-up duration was $120.4 \pm 54.2$ months (range, $71-391$ ). The study was conducted in accordance with the Declaration of Helsinki (as revised in 2013) and was approved by Yonsei University's institutional review board (IRB No.: 4-20190146), which waived the requirement for informed consent due to the retrospective nature of this study.

2.2. Postoperative Management and Follow-Up. All pediatric and adult patients were postoperatively managed according to the ATA management guidelines for children [12] and adults [15], respectively. RAI ablation was performed 4 to 6 weeks postoperatively using doses based on ATA guidelines. Whole-body scans (WBS) were performed after 5 to 7 days of RAI ablation in patients who underwent TT. Thyroglobulin (Tg) and antithyroglobulin antibody (TgAb) concentrations were assessed after TSH stimulation by T4 withdrawal or recombinant human TSH injection before RAI ablation. All patients received L-thyroxine with suppressive doses and were regularly followed up with physical examination, thyroid function tests, assessment of $\mathrm{Tg}$ and
TgAb concentrations, and neck ultrasonography every 3 to 6 months and annually thereafter. Patients who presented with evidence of recurrence or distant metastasis on routine follow-up evaluations were assessed by additional diagnostic imaging, including computed tomography, positron emission tomography-computed tomography, and/or RAI WBS, to determine the location and extent of suspected recurrence. Disease recurrence was confirmed by imaging modalities and/or pathologic diagnosis using ultrasonography-guided fine-needle aspiration.

2.3. Statistical Analysis. Continuous and quantitative variables are presented as means and standard deviation (SD). Categorical and qualitative variables are reported as numbers with percentages. Student's $t$-test, chi-square test, or Wilcoxon rank-sum test was used for group comparisons. Univariate and multivariate Cox regression analyses were performed to identify independent predictors of DFS. Hazard ratios (HRs) with 95\% confidence intervals (CIs) were calculated. DFS was analyzed for the three study groups using Kaplan-Meier survival analysis with a log-rank test. $P<0.05$ was considered statistically significant. All statistical analyses were performed with the software package SPSS (version 23.0 for Windows; SPSS, Chicago, IL).

\section{Results}

3.1. Comparison among Different Age Groups. A total of 98 pediatric, 1261 young adult, and 4017 adult patients were enrolled in this study. Table 1 presents the results of the comparison of baseline clinicopathological characteristics among the different age groups. The mean tumor size was significantly larger in the pediatric group than in the adult groups $(2.1 \pm 1.3$ versus $1.3 \pm 1.0$ versus $1.0 \pm 0.8, p<0.001$ and $p<0.001)$. The proportion of FTC was significantly higher in pediatric patients $(7.1 \%$ versus $1.6 \%$ versus $0.7 \%$, $p=0.002$ and $p<0.001)$. With regard to pathological $\mathrm{T}$ and $\mathrm{N}$ stages, the pediatric group exhibited a significantly higher grade. The recurrence rate was significantly higher in the pediatric group $(14.3 \%$ versus $6.6 \%$ versus $3.0 \%, p=0.004$ and $p<0.001)$. No significant differences were observed in gender, multifocality, bilaterality, or ETE among groups. Table 2 presents the results of the comparison of management among the different age groups. The proportion of TT and $\mathrm{mRND}$ was significantly higher in the pediatric group than in the young adult and the adult groups (TT, $p<0.001$ and $p<0.001 ; \mathrm{mRND} ; p<0.001$ and $p<0.001$, respectively).

3.2. Risk Analysis for DFS in Different Age Groups. Univariate and multivariate Cox regression analyses were performed to identify independent risk factors for DFS (Table 3). In univariate analysis, the pediatric group was identified as a significant risk factor for DFS (young adult group: HR, 0.437; 95\% CI, 0.252-0.757; $p=0.003$; adult group: HR, 0.210 ; 95\% CI, 0.123-0.359; $p<0.001)$. Multivariate analysis revealed that the adult group had a significantly lower risk of DFS (HR, 0.362; 95\% CI, 0.210-0.625; $p<0.001)$. Tumor size over $1 \mathrm{~cm}$ (HR, 2.272; 95\% CI, 
TABLE 1: Comparison of clinicopathological characteristics among groups.

\begin{tabular}{|c|c|c|c|c|c|}
\hline & $\begin{array}{c}<20 \text { years old }(\mathrm{A}) \\
(n=98)\end{array}$ & $\begin{array}{c}20-29 \text { years old }(\mathrm{B}) \\
(n=1261)\end{array}$ & $\begin{array}{c}30-39 \text { years old }(\mathrm{C}) \\
(n=4017)\end{array}$ & $p$ value (A versus $B)$ & $p$ value (A versus $C$ ) \\
\hline Age (years) & $16.7 \pm 3.0$ & $26.2 \pm 2.5$ & $34.8 \pm 2.8$ & $<0.001$ & $<0.001$ \\
\hline Male : female & $1: 7.9$ & $1: 7.2$ & $1: 5.2$ & 0.873 & 0.211 \\
\hline Male & $11(11.2 \%)$ & $153(12.1 \%)$ & $650(16.2 \%)$ & & \\
\hline Female & $87(88.8 \%)$ & $1108(87.9 \%)$ & $3367(83.8 \%)$ & & \\
\hline Tumor size $(\mathrm{cm})$ & $2.1 \pm 1.3$ & $1.3 \pm 1.0$ & $1.0 \pm 0.8$ & $<0.001$ & $<0.001$ \\
\hline $\begin{array}{l}\text { Type of } \\
\text { carcinoma }\end{array}$ & & & & 0.002 & $<0.001$ \\
\hline PTC & $91(92.9 \%)$ & $1241(98.4 \%)$ & $3989(99.3 \%)$ & & \\
\hline FTC & $7(7.1 \%)$ & $20(1.6 \%)$ & $28(0.7 \%)$ & & \\
\hline Multifocality & $24(24.5 \%)$ & $284(22.5 \%)$ & $975(34.3 \%)$ & 0.619 & 0.520 \\
\hline Bilaterality & $15(15.3 \%)$ & $173(13.7 \%)$ & $592(14.7 \%)$ & 0.649 & 0.885 \\
\hline ETE & $36(36.7 \%)$ & $359(28.5 \%)$ & $610(15.2 \%)$ & 0.402 & 0.153 \\
\hline T stage & & & & $<0.001$ & $<0.001$ \\
\hline $\mathrm{T} 1$ & $44(44.9 \%)$ & $815(64.7 \%)$ & $3248(80.9 \%)$ & & \\
\hline $\mathrm{T} 2$ & $17(17.3 \%)$ & $85(6.7 \%)$ & $154(3.8 \%)$ & & \\
\hline $\mathrm{T} 3$ & $33(33.7 \%)$ & $342(27.1 \%)$ & $558(13.9 \%)$ & & \\
\hline $\mathrm{T} 4$ & $4(4.1 \%)$ & $19(1.5 \%)$ & $57(1.4 \%)$ & & \\
\hline $\mathrm{N}$ stage & & & & $<0.001$ & $<0.001$ \\
\hline No & $25(25.5 \%)$ & $577(45.8 \%)$ & $2255(56.2 \%)$ & & \\
\hline N1a & $43(43.9 \%)$ & $454(36.0 \%)$ & $1331(33.1 \%)$ & & \\
\hline $\mathrm{N} 1 \mathrm{~b}$ & $30(30.6 \%)$ & $230(18.2 \%)$ & $431(10.7 \%)$ & & \\
\hline M stage & & & & 0.064 & 0.018 \\
\hline M1 & $2(2.0 \%)$ & $4(0.3 \%)$ & $7(0.2 \%)$ & & \\
\hline Recurrence & $14(14.3 \%)$ & $83(6.6 \%)$ & $121(3.0 \%)$ & 0.004 & $<0.001$ \\
\hline
\end{tabular}

Data are expressed as patient's number (\%) or mean \pm SD. A statistically significant difference was defined as $p<0.05$. PTC, papillary thyroid carcinoma; FTC, follicular thyroid carcinoma; ETE, extrathyroidal extension; T, tumor; N, node; $M$, metastasis.

TABLE 2: Comparison of management among groups.

\begin{tabular}{|c|c|c|c|c|c|}
\hline & $\begin{array}{c}<20 \text { years old }(\mathrm{A}) \\
(n=98)\end{array}$ & $\begin{array}{c}20-29 \text { years old }(\mathrm{B}) \\
(n=1261)\end{array}$ & $\begin{array}{c}30-39 \text { years old }(\mathrm{C}) \\
(n=4017)\end{array}$ & $p$ value (A versus $B)$ & $p$ value (A versus $C$ ) \\
\hline $\begin{array}{l}\text { Extent of } \\
\text { operation }\end{array}$ & & & & $<0.001$ & $<0.001$ \\
\hline Less than TT & $36(36.7 \%)$ & $605(48.0 \%)$ & $1979(49.3 \%)$ & & \\
\hline $\mathrm{TT}$ & $62(63.3 \%)$ & $656(52.0 \%)$ & $2038(50.7 \%)$ & & \\
\hline Node dissection & & & & $<0.001$ & $<0.001$ \\
\hline CCND & $68(69.4 \%)$ & $1031(81.8 \%)$ & $3586(89.3 \%)$ & & \\
\hline mRND & $30(30.6 \%)$ & $230(18.2 \%)$ & $431(10.7 \%)$ & & \\
\hline $\begin{array}{l}\text { RAI therapy } \\
(\mathrm{mCi})\end{array}$ & & & & 0.141 & 0.065 \\
\hline No & $44(44.9 \%)$ & $670(53.1 \%)$ & $2189(54.5 \%)$ & & \\
\hline 30 & $30(30.6 \%)$ & $423(33.5 \%)$ & $1424(35.5 \%)$ & & \\
\hline $100-150$ & $21(21.4 \%)$ & $147(11.7 \%)$ & $367(9.1 \%)$ & & \\
\hline 200 & $1(1.0 \%)$ & $19(1.5 \%)$ & $33(0.8 \%)$ & & \\
\hline$>200$ & $2(2.1 \%)$ & $2(0.2 \%)$ & $4(0.1 \%)$ & & \\
\hline
\end{tabular}

Data are expressed as patient's number (\%). A statistically significant difference was defined as $p<0.05$. TT, total thyroidectomy; CCND, central compartment neck dissection; mRND, modified radical neck dissection; RAI, radioactive iodine.

1.673-3.086; $p<0.001)$, Nla stage (HR, 2.074; 95\% CI, $1.477-2.911 ; p<0.001)$, and N1b stage (HR, 3.267; 95\% CI, 2.256-4.732; $p<0.001)$ were identified as significant risk factors for DFS in multivariate analysis. Kaplan-Meier analysis revealed a significant difference in DFS between the pediatric group and adult groups (pediatric versus young adult group, $p=0.002$; pediatric versus adult group, $p<0.001$; Figure 1).
3.3. Subanalysis of Pediatric Subgroups. Tables 4 and 5 present the results of subanalyses of clinicopathological characteristics and management in pediatric subgroups $(\leq 16$ years old or 17-19 years old). No significant differences were observed in tumor size, type of carcinoma, multifocality, bilaterality, or M stage between the two pediatric subgroups. The proportion of female patients was significantly higher in the older pediatric group than in the younger pediatric 
TABLE 3: Univariate and multivariate analyses for DFS in different age groups.

\begin{tabular}{|c|c|c|c|c|}
\hline & \multicolumn{2}{|c|}{ Univariate } & \multicolumn{2}{|c|}{ Multivariate } \\
\hline & $\mathrm{HR}(95 \% \mathrm{CI})$ & $\begin{array}{c}p \\
\text { value }\end{array}$ & HR $(95 \% \mathrm{CI})$ & $\begin{array}{c}p \\
\text { value }\end{array}$ \\
\hline \multicolumn{5}{|l|}{ Age (years) } \\
\hline$<20$ & Ref. & & Ref. & \\
\hline $20-29$ & $\begin{array}{c}0.437 \\
(0.252-0.757)\end{array}$ & 0.003 & $\begin{array}{c}0.599 \\
(0.345-1.040)\end{array}$ & 0.069 \\
\hline $30-39$ & $\begin{array}{c}0.210 \\
(0.123-0.359)\end{array}$ & $<0.001$ & $\begin{array}{c}0.362 \\
(0.210-0.625)\end{array}$ & $<0.001$ \\
\hline \multicolumn{5}{|l|}{ Tumor size } \\
\hline$\leq 1 \mathrm{~cm}$ & Ref. & & Ref. & \\
\hline$>1 \mathrm{~cm}$ & $\begin{array}{c}3.354 \\
(2.509-4.484)\end{array}$ & $<0.001$ & $\begin{array}{c}2.272 \\
(1.673-3.086)\end{array}$ & $<0.001$ \\
\hline ETE & $\begin{array}{c}1.752 \\
(1.332-2.303)\end{array}$ & $<0.001$ & & \\
\hline Multifocality & $\begin{array}{c}1.495 \\
(1.124-1.988)\end{array}$ & 0.006 & & \\
\hline Bilaterality & $\begin{array}{c}1.837 \\
(1.346-2.508)\end{array}$ & $<0.001$ & & \\
\hline \multicolumn{5}{|l|}{ T stage } \\
\hline $\mathrm{T} 1$ & Ref. & & & \\
\hline $\mathrm{T} 2$ & $\begin{array}{c}2.267 \\
(1.244-4.131)\end{array}$ & 0.008 & & \\
\hline T3 & $\begin{array}{c}1.950 \\
(1.448-2.627)\end{array}$ & $<0.001$ & & \\
\hline $\mathrm{T} 4$ & $\begin{array}{c}4.860 \\
(2.564-9.213)\end{array}$ & $<0.001$ & & \\
\hline \multicolumn{5}{|l|}{$\mathrm{N}$ stage } \\
\hline No & Ref. & - & Ref. & - \\
\hline N1a & $\begin{array}{c}2.596 \\
(1.862-3.619)\end{array}$ & $<0.001$ & $\begin{array}{c}2.074 \\
(1.477-2.911)\end{array}$ & $<0.001$ \\
\hline N1b & $\begin{array}{c}5.129 \\
(3.613-7.283)\end{array}$ & $<0.001$ & $\begin{array}{c}3.267 \\
(2.256-4.732)\end{array}$ & $<0.001$ \\
\hline \multicolumn{5}{|l|}{ RAI therapy } \\
\hline No & Ref. & - & & \\
\hline yes & $\begin{array}{c}1.709 \\
(1.303-2.244)\end{array}$ & $<0.001$ & & \\
\hline
\end{tabular}

Data are expressed as hazard ratio (HR) and $95 \%$ confidence interval (CI). A statistically significant difference was defined as $p<0.05$. ETE, extrathyroidal extension; T, tumor; N, node; RAI, radioactive iodine.

group $(81.1 \%$ versus $93.4 \%, p<0.001)$. The ETE was significantly greater in the younger pediatric group than in the older pediatric group $(51.4 \%$ versus $27.9 \%, p=0.007)$. The younger pediatric group exhibited a significantly higher grade of pathological $\mathrm{T}$ and $\mathrm{N}$ stage compared to the older pediatric group $(p=0.012$ and $p<0.001)$. The proportion of TT and mRND was significantly higher in the younger pediatric group than in the older pediatric group $(81.1 \%$ versus $52.5 \%, p=0.010$, and $54.1 \%$ versus $16.4 \%, p<0.001$, respectively). In total, six (16.2\%) patients in the younger pediatric group and eight (13.1\%) patients in the older pediatric group were diagnosed with recurrence, but this difference was not significant $(p=0.564)$.

3.4. Subanalysis of Older Pediatric Subgroup and Adult Groups. Tables 6 and 7 present the results of the subanalyses of clinicopathological characteristics and management of the

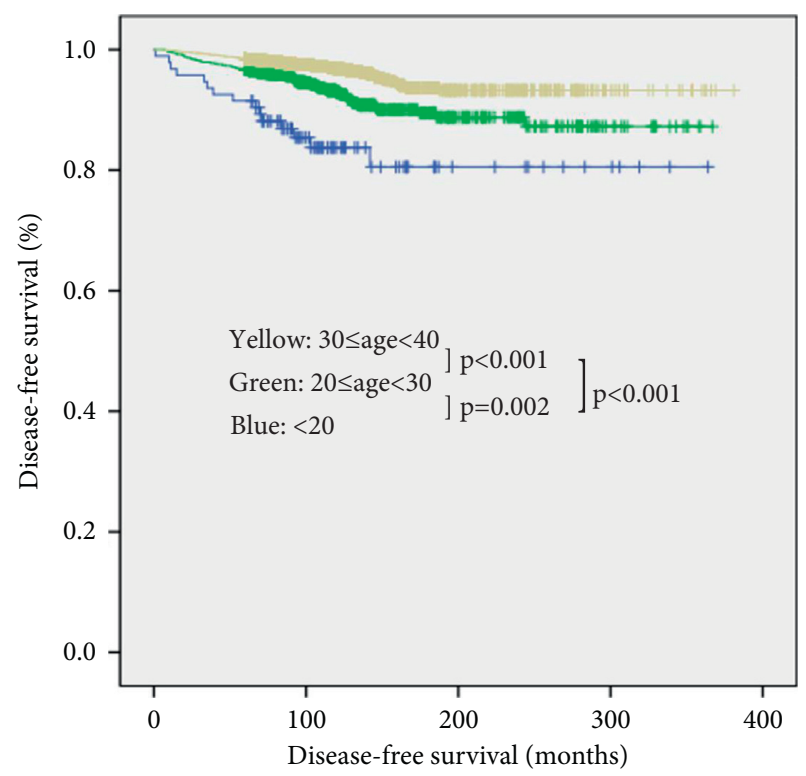

FIgURE 1: Disease-free survival curves of three groups (log rank; $<20$ versus $20-29$ years, $p=0.002 ;<20$ versus $30-39$ years, $p<0.001 ; 20-29$ years versus $30-39$ years, $p<0.001$ ).

TABLE 4: Subanalysis of clinicopathological characteristics in pediatric subgroups.

\begin{tabular}{|c|c|c|c|}
\hline & $\begin{array}{c}\leq 16 \text { years } \\
(n=37)\end{array}$ & $\begin{array}{c}17-19 \text { years } \\
(n=61)\end{array}$ & $p$ value \\
\hline$\overline{\text { Age (years) }}$ & $13.9 \pm 3.1$ & $18.4 \pm 0.8$ & $<0.001$ \\
\hline Male : female & $1: 4.3$ & $1: 14.3$ & $<0.001$ \\
\hline Male & $7(18.9 \%)$ & $4(6.6 \%)$ & \\
\hline Female & $30(81.1 \%)$ & $57(93.4 \%)$ & \\
\hline Tumor size $(\mathrm{cm})$ & $2.3 \pm 1.0$ & $1.9 \pm 1.5$ & 0.205 \\
\hline $\begin{array}{l}\text { Type of } \\
\text { carcinoma }\end{array}$ & & & 0.184 \\
\hline PTC & $36(97.3 \%)$ & $55(90.2 \%)$ & \\
\hline FTC & $1(2.7 \%)$ & $6(9.8 \%)$ & \\
\hline Multifocality & $10(27.0 \%)$ & $14(23.0 \%)$ & 0.809 \\
\hline Bilaterality & $8(21.6 \%)$ & $7(11.5 \%)$ & 0.247 \\
\hline ETE & $19(51.4 \%)$ & $17(27.9 \%)$ & 0.007 \\
\hline T stage & & & 0.012 \\
\hline $\mathrm{T} 1$ & $10(27.0 \%)$ & $34(55.7 \%)$ & \\
\hline $\mathrm{T} 2$ & $8(21.6 \%)$ & $9(14.8 \%)$ & \\
\hline $\mathrm{T} 3$ & $16(43.2 \%)$ & $17(27.9 \%)$ & \\
\hline $\mathrm{T} 4$ & $3(8.1 \%)$ & $1(1.6 \%)$ & \\
\hline $\mathrm{N}$ stage & & & $<0.001$ \\
\hline No & $7(18.9 \%)$ & $18(29.5 \%)$ & \\
\hline N1a & $10(27.0 \%)$ & $33(54.1 \%)$ & \\
\hline N1b & $20(54.1 \%)$ & $10(16.4 \%)$ & \\
\hline M stage & & & 0.718 \\
\hline M1 & $1(2.7 \%)$ & $1(1.6 \%)$ & \\
\hline Recurrence & $6(16.2 \%)$ & $8(13.1 \%)$ & 0.564 \\
\hline
\end{tabular}

Data are expressed as patient's number (\%) or mean \pm SD. A statistically significant difference was defined as $p<0.05$. PTC, papillary thyroid carcinoma; FTC, follicular thyroid carcinoma; ETE, extrathyroidal extension; $\mathrm{T}$, tumor; $\mathrm{N}$, node; $\mathrm{M}$, metastasis.

three different groups over 16 years of age. No significant differences in most of clinicopathological characteristics were identified relative to the results presented in Table 1. 
TABLE 5: Subanalysis of management in pediatric subgroups.

\begin{tabular}{|c|c|c|c|}
\hline & $\leq 16$ years $(n=37)$ & $17-19$ years $(n=61)$ & $p$ value \\
\hline Extent of operation & & & 0.010 \\
\hline Less than TT & $7(18.9 \%)$ & $29(47.5 \%)$ & \\
\hline $\mathrm{TT}$ & $30(81.1 \%)$ & $32(52.5 \%)$ & \\
\hline Node dissection & & & $<0.001$ \\
\hline CCND & $17(45.9 \%)$ & $51(83.6 \%)$ & \\
\hline mRND & $20(54.1 \%)$ & $10(16.4 \%)$ & \\
\hline RAI therapy (mCi) & & & 0.147 \\
\hline No & $13(35.1 \%)$ & $31(50.8 \%)$ & \\
\hline 30 & $12(32.4 \%)$ & $18(29.5 \%)$ & \\
\hline $100-150$ & $10(27.0 \%)$ & $11(18.0 \%)$ & \\
\hline 200 & $0(0 \%)$ & $1(1.6 \%)$ & \\
\hline$>200$ & $2(5.4 \%)$ & $0(0 \%)$ & \\
\hline
\end{tabular}

Data are expressed as patient's number (\%). A statistically significant difference was defined as $p<0.05$. TT, total thyroidectomy; CCND, central compartment neck dissection; mRND, modified radical neck dissection; RAI, radioactive iodine.

TABLE 6: Subanalysis of clinicopathological characteristics of groups over 16 years of age.

\begin{tabular}{|c|c|c|c|c|c|}
\hline & $\begin{array}{c}17-19 \text { years }(\mathrm{A}) \\
(n=61)\end{array}$ & $\begin{array}{c}20-29 \text { years old }(\mathrm{B}) \\
(n=1261)\end{array}$ & $\begin{array}{c}30-39 \text { years old }(C) \\
(n=4017)\end{array}$ & $p$ value (A versus $B)$ & $p$ value (A versus $C$ ) \\
\hline Age (years) & $18.4 \pm 0.8$ & $26.2 \pm 2.5$ & $34.8 \pm 2.8$ & $<0.001$ & $<0.001$ \\
\hline Male : female & $1: 14.3$ & $1: 7.2$ & $1: 5.2$ & 0.227 & 0.051 \\
\hline Male & $4(6.6 \%)$ & $153(12.1 \%)$ & $650(16.2 \%)$ & & \\
\hline Female & $57(93.4 \%)$ & $1108(87.9 \%)$ & $3367(83.8 \%)$ & & \\
\hline Tumor size $(\mathrm{cm})$ & $1.9 \pm 1.5$ & $1.3 \pm 1.0$ & $1.0 \pm 0.8$ & $<0.001$ & $<0.001$ \\
\hline $\begin{array}{l}\text { Type of } \\
\text { carcinoma }\end{array}$ & & & & 0.001 & $<0001$ \\
\hline PTC & $55(90.2 \%)$ & $1241(98.4 \%)$ & $3989(99.3 \%)$ & & \\
\hline FTC & $6(9.8 \%)$ & $20(1.6 \%)$ & $28(0.7 \%)$ & & \\
\hline Multifocality & $14(23.0 \%)$ & $284(22.5 \%)$ & $975(34.3 \%)$ & 0.938 & 0.881 \\
\hline Bilaterality & $7(11.5 \%)$ & $173(13.7 \%)$ & $592(14.7 \%)$ & 0.848 & 0.586 \\
\hline ETE & $17(27.9 \%)$ & $359(28.5 \%)$ & $610(15.2 \%)$ & 0.432 & 0.699 \\
\hline T stage & & & & 0.001 & $<0.001$ \\
\hline $\mathrm{T} 1$ & $34(55.7 \%)$ & $815(64.7 \%)$ & $3248(80.9 \%)$ & & \\
\hline $\mathrm{T} 2$ & $9(14.8 \%)$ & $85(6.7 \%)$ & $154(3.8 \%)$ & & \\
\hline $\mathrm{T} 3$ & $17(27.9 \%)$ & $342(27.1 \%)$ & $558(13.9 \%)$ & & \\
\hline $\mathrm{T} 4$ & $1(1.6 \%)$ & $19(1.5 \%)$ & $57(1.4 \%)$ & & \\
\hline $\mathrm{N}$ stage & & & & 0.039 & $<0.001$ \\
\hline No & $18(29.5 \%)$ & $577(45.8 \%)$ & $2255(56.2 \%)$ & & \\
\hline N1a & $33(54.1 \%)$ & $454(36.0 \%)$ & $1331(33.1 \%)$ & & \\
\hline N1b & $10(16.4 \%)$ & $230(18.2 \%)$ & $431(10.7 \%)$ & & \\
\hline M stage & & & & 0.211 & 0.114 \\
\hline M1 & $1(1.6 \%)$ & $4(0.3 \%)$ & $7(0.2 \%)$ & & \\
\hline Recurrence & $8(13.1 \%)$ & $83(6.6 \%)$ & $121(3.0 \%)$ & 0.064 & 0.001 \\
\hline
\end{tabular}

Data are expressed as patient's number (\%) or mean \pm SD. A statistically significant difference was defined as $p<0.05$. PTC, papillary thyroid carcinoma; FTC, follicular thyroid carcinoma; ETE, extrathyroidal extension; T, tumor; N, node; M, metastasis.

However, the recurrence rate did not differ between the older pediatric and the young adult groups $(13.1 \%$ versus $6.6 \%, p=0.064)$. The extent of operation and RAI therapy were not significantly different.

Univariate and multivariate logistic regression analyses were performed to determine independent risk factors for DFS (Table 8). Results were similar to those presented in Table 3. Only the adult group was not identified as a significant independent risk factor for DFS in multivariate analysis (HR, 0.362 ; 95\% CI, 0.206 to $0.627 ; p=0.006$ ). In Kaplan-Meier analysis, no significant difference was observed in DFS between the younger pediatric and older pediatric groups ( $p=0.560$; Figure 2$)$. Significant differences in DFS were observed between the older pediatric group and adult groups (older pediatric versus young adult group, $p=0.042$; older pediatric versus adult group, $p<0.001$; Figure 2).

3.5. Subanalysis of Patients in Different Age Groups with Tumor Size of 2 to $4 \mathrm{~cm}$. Given that the majority of pediatric patients were diagnosed with palpable masses rather than by a screening test, we reanalyzed the patients with tumor sizes of 2 to $4 \mathrm{~cm}$. In total, 47 pediatric, 187 young adult, and 367 
TABLE 7: Subanalysis of treatment management of groups over 16 years of age.

\begin{tabular}{|c|c|c|c|c|c|}
\hline & $\begin{array}{c}17-19 \text { years }(\mathrm{A}) \\
(n=61)\end{array}$ & $\begin{array}{c}20-29 \text { years old }(\mathrm{B}) \\
(n=1261)\end{array}$ & $\begin{array}{c}30-39 \text { years old }(\mathrm{C}) \\
(n=4017)\end{array}$ & $p$ value (A versus $\mathrm{B})$ & $p$ value (A versus $C$ ) \\
\hline $\begin{array}{l}\text { Extent of } \\
\text { operation }\end{array}$ & & & & 0.126 & 0.153 \\
\hline Less than TT & $29(47.5 \%)$ & $605(48.0 \%)$ & $1979(49.3 \%)$ & & \\
\hline TT & $32(52.5 \%)$ & $656(52.0 \%)$ & $2038(50.7 \%)$ & & \\
\hline Node dissection & & & & 0.967 & 0.092 \\
\hline CCND & $51(83.6 \%)$ & $1031(81.8 \%)$ & $3586(89.3 \%)$ & & \\
\hline mRND & $10(16.4 \%)$ & $230(18.2 \%)$ & $431(10.7 \%)$ & & \\
\hline $\begin{array}{l}\text { RAI therapy } \\
(\mathrm{mCi})\end{array}$ & & & & 0.851 & 0.351 \\
\hline No & $31(50.8 \%)$ & $670(53.1 \%)$ & $2189(54.5 \%)$ & & \\
\hline 30 & $18(29.5 \%)$ & $423(33.5 \%)$ & $1424(35.5 \%)$ & & \\
\hline $100-150$ & $11(18.0 \%)$ & $147(11.7 \%)$ & $367(9.1 \%)$ & & \\
\hline 200 & $1(1.6 \%)$ & $19(1.5 \%)$ & $33(0.8 \%)$ & & \\
\hline$>200$ & $0(0 \%)$ & $2(0.2 \%)$ & $4(0.1 \%)$ & & \\
\hline
\end{tabular}

Data are expressed as patient's number (\%). A statistically significant difference was defined as $p<0.05$. TT, total thyroidectomy; CCND, central compartment neck dissection; mRND, modified radical neck dissection; RAI, radioactive iodine.

adult patients were included in the reanalysis. Table 9 presents the results of the comparison of clinicopathological characteristics among the three different age groups with tumor sizes of 2 to $4 \mathrm{~cm}$. No significant differences were observed in the proportion of males, type of carcinoma, multifocality, bilaterality, ETE, and pathological $\mathrm{T}$ or $\mathrm{M}$ stage. The pediatric group presented with a significantly higher grade in the pathological $\mathrm{N}$ stage $(p=0.006)$. Recurrence rate was significantly higher in the pediatric group (25.5\% versus $16.6 \%$ versus $9.5 \%, p=0.001)$.

3.6. Risk Subanalysis for DFS in Patients in Different Age Groups with Tumor Size of 2 to $4 \mathrm{~cm}$. Univariate and multivariate logistic regression analyses were performed to determine independent risk factors for DFS in patients with tumor sizes of 2 to $4 \mathrm{~cm}$ (Table 10). Among the three different age groups, only the adult group was not a significant risk factor for DFS in both univariate and multivariate analyses (HR, 0.292; 95\% CI, 0.151-0.563; $p<0.001$; and HR, 0.305 ; 95\% CI, 0.158-0.588; $p<0.001$, respectively). Bilaterality (HR, 1.758; 95\% CI, 1.061-2.913; $p=0.029)$ was confirmed as a significant risk factor for DFS in multivariate analysis. Kaplan-Meier analysis revealed significant differences in DFS between the pediatric group and adult groups (pediatric versus young adult group, $p=0.045$; and pediatric versus adult group, $p<0.001$; Figure 3).

\section{Discussion}

Pediatric and adult DTCs are considered distinct diseases, as the former is underscored by more aggressive features but a more favorable long-term prognosis $[9,11,16]$. Age is a major prognostic factor in DTC [17]. Therefore, the TNM staging system of DTC is classified according to an age of 55 years. Nevertheless, few studies have compared clinical presentation and surgical outcomes between pediatric and adult patients with DTC $[18,19]$. Here, we investigated the clinicopathological characteristics of 5376 patients with DTC to investigate the effects of age on surgical outcomes.
In this study, tumor size was larger in pediatric patients. Kim et al. reported that tumor size was larger in pediatric patients than in young adult patients [19]. However, no significant differences were observed in multifocal and bilateral disease between pediatric and adult groups, in contrast to previous reports [20-23]. Several reports have indicated that the incidence of multifocality in pediatric patients may reach $88 \%[24,25]$. The ETE appeared to be more common in pediatric DTC, but we did not identify a significant difference in this regard. The thyroid gland is smaller in children than in adults, which may facilitate the occurrence of early capsular extension [26]. T, N, and M staging grade and the recurrence rate were significantly higher in the pediatric group than in the adult groups. These results were consistent with previous reports on the characteristics of pediatric DTC [27-30]. Nevertheless, the factors underpinning the more aggressive features of pediatric DTC have not been fully elucidated.

Based on the mean age of pediatric patients (16.7 years), we performed a subanalysis of the pediatric group. The ETE was more prevalent in the younger pediatric group $(\leq 16$ years old) than in the older pediatric group (17-19 years old). Further, the younger pediatric group presented with a significantly higher grade of $\mathrm{T}$ and $\mathrm{N}$ stage compared with the older pediatric group. These findings are consistent with previous reports [27,31,32]. Nevertheless, no significant differences were observed in multifocality, bilaterality, and ETE between adolescent and adult groups. Adolescent DTC tended to be similar to that in young adults, even the recurrence rate.

In multivariate analysis, only the adult group was not identified as a significant independent risk factor for DFS, suggesting that pediatric and young adult DTC have similar clinical outcomes. In addition, the frequency of intensive treatment, such as TT, mRND, and high-dose RAI therapy $(>100 \mathrm{mCi})$, was significantly higher in the pediatric group than in the adult groups. These factors may have contributed to the similar prognosis of pediatric and young adult DTC. 
TABLE 8: Univariate and multivariate analyses for DFS in different age groups.

\begin{tabular}{|c|c|c|c|c|}
\hline & \multicolumn{2}{|c|}{ Univariate } & \multicolumn{2}{|c|}{ Multivariate } \\
\hline & HR (95\% CI) & $\underset{\text { value }}{p}$ & HR (95\% CI) & $\begin{array}{c}p \\
\text { value }\end{array}$ \\
\hline \multicolumn{5}{|l|}{ Age (years) } \\
\hline $17-19$ & Ref. & & Ref. & \\
\hline $20-29$ & $\begin{array}{c}0.477 \\
(0.242-0.826)\end{array}$ & 0.046 & $\begin{array}{c}0.561 \\
(0.337-1.117)\end{array}$ & 0.156 \\
\hline $30-39$ & $\begin{array}{c}0.230 \\
(0.110-0.387)\end{array}$ & $<0.001$ & $\begin{array}{c}0.362 \\
(0.206-0.627)\end{array}$ & 0.006 \\
\hline \multicolumn{5}{|l|}{ Tumor size } \\
\hline$\leq 1 \mathrm{~cm}$ & Ref. & & Ref. & \\
\hline$>1 \mathrm{~cm}$ & $\begin{array}{c}3.228 \\
(2.411-4.648)\end{array}$ & $<0.001$ & $\begin{array}{c}2.417 \\
(1.594-3.163)\end{array}$ & $<0.001$ \\
\hline ETE & $\begin{array}{c}1.704 \\
(1.295-2.412)\end{array}$ & $<0.001$ & & \\
\hline Multifocality & $\begin{array}{c}1.427 \\
(1.103-1.864)\end{array}$ & 0.006 & & \\
\hline Bilaterality & $\begin{array}{c}1.801 \\
(1.294-2.576)\end{array}$ & $<0.001$ & $\begin{array}{c}1.470 \\
(0.954-1.932)\end{array}$ & 0.026 \\
\hline \multicolumn{5}{|l|}{ T stage } \\
\hline $\mathrm{T} 1$ & Ref. & & & \\
\hline $\mathrm{T} 2$ & $\begin{array}{c}2.346 \\
(1.216-4.215)\end{array}$ & 0.005 & & \\
\hline T3 & $\begin{array}{c}1.936 \\
(1.426-2.518)\end{array}$ & $<0.001$ & & \\
\hline $\mathrm{T} 4$ & $\begin{array}{c}4.195 \\
(2.286-8.639)\end{array}$ & $<0.001$ & & \\
\hline \multicolumn{5}{|l|}{$\mathrm{N}$ stage } \\
\hline No & Ref. & - & Ref. & - \\
\hline N1a & $\begin{array}{c}2.692 \\
(1.749-3.943)\end{array}$ & $<0.001$ & $\begin{array}{c}2.349 \\
(1.256-2.984)\end{array}$ & $<0.001$ \\
\hline N1b & $\begin{array}{c}5.095 \\
(3.437-7.842)\end{array}$ & $<0.001$ & $\begin{array}{c}4.046 \\
(2.547-5.438)\end{array}$ & $<0.001$ \\
\hline \multicolumn{5}{|l|}{ RAI therapy } \\
\hline No & Ref. & - & & \\
\hline yes & $\begin{array}{c}1.785 \\
(1.203-2.548)\end{array}$ & $<0.001$ & & \\
\hline
\end{tabular}

Data are expressed as hazard ratio (HR) and $95 \%$ confidence interval (CI). A statistically significant difference was defined as $p<0.05$. ETE, extrathyroidal extension; $\mathrm{T}$, tumor; $\mathrm{N}$, node; $\mathrm{RAI}$, radioactive iodine.

In general, most of adult DTCs were diagnosed with a screening test, whereas most of pediatric DTCs were incidentally diagnosed. Physical examination is important given that palpable masses are more common in pediatric patients than in adult patients [10,33-35]. Indeed, $31-97 \%$ of pediatric patients with DTC present with a bulge in the anterior neck $[4,10,36]$. However, this manifestation is asymptomatic in childhood and is often noticed by parents or medical staff, rendering an early diagnosis of pediatric patients challenging. In this study, the mean tumor size of pediatric DTC was significantly larger than that of adult DTC. Further, we performed a subanalysis of clinicopathological characteristics in three different age groups with a tumor size of 2 to $4 \mathrm{~cm}$. Despite adjusting for size differences, the recurrence rate was significantly higher in the pediatric group than in the adult groups $(25.5 \%$ versus $16.6 \%$ versus $9.5 \%, p=0.001)$. Multivariate analysis revealed similar results to the preceding analyses. Our findings suggest that the

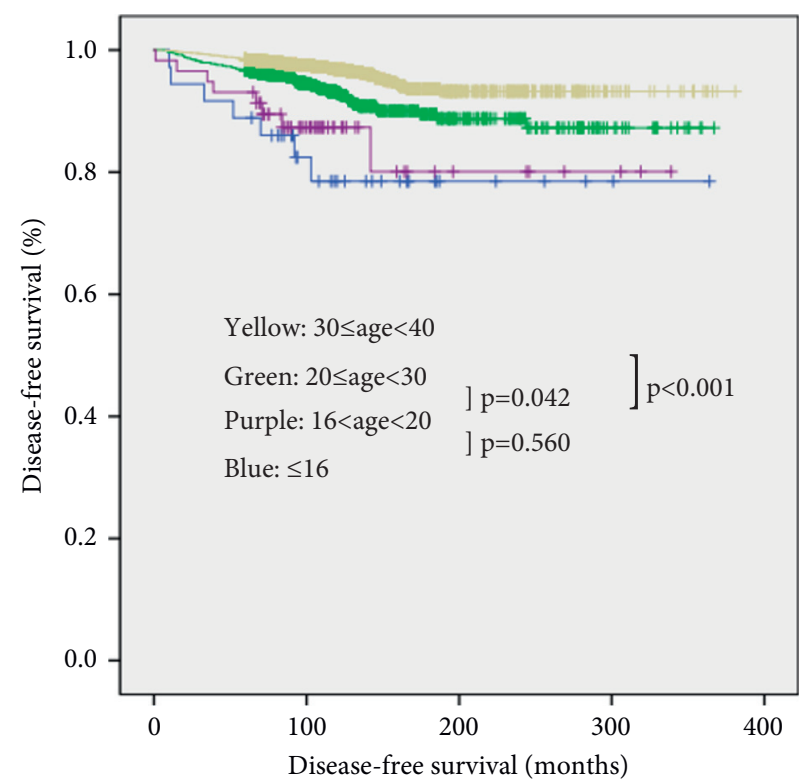

FIGURE 2: Disease-free survival curves of four groups (log rank; $\leq 16$ years versus $17-19$ years, $p=0.560 ; 17-19$ years versus $20-29$ years, $p=0.042 ; 17-19$ years versus $30-39$ years, $p<0.001$ ).

prognosis of pediatric DTC is affected by other risk factors, such as age and bilaterality, in addition to tumor size. Jarzab et al. reported that younger children had a poorer prognosis compared to older children [32]. Additionally, Palmer et al. demonstrated that one of the best predictors of recurrence was multiple thyroid nodules at presentation [37].

The causative factors of differences in clinicopathological features and long-term outcomes between pediatric and adult DTC are obscure. One possible factor is differences in molecular pathogenesis between pediatric and adult DTC. Genetic studies of DTC indicate that the most common genetic defect is RET/PTC rearrangements in pediatric DTC, whereas $\mathrm{BRAF}^{\mathrm{V} 600 \mathrm{E}}$ and RAS mutations are most commonly detected in adult DTC [9, 38-40]. Additionally, the level of sodium-iodide symporter (NIS) gene expression is higher in pediatric DTC than in adult DTC [41, 42]. This implies greater responsiveness to RAI and better therapeutic outcomes in pediatric DTC than in adult DTC $[42,43]$.

According to the ATA management guidelines for children, TT is recommended in pediatric DTC due to the more aggressive features and increased risk of recurrence in pediatric DTC [12]. In addition, TT has several advantages, such as guaranteed RAI ablation and the use of $\mathrm{Tg}$ as a tumor marker. Nevertheless, TT is associated with various complications, including transient/permanent postoperative hypoparathyroidism, recurrent laryngeal nerve injury, and side effects due to lifetime TSH suppression. In this study, none of the pediatric patients developed permanent complications. Conservative surgical management is recommended to avoid surgical complications in pediatric patients with the nonadvanced disease. The optimal extent of operation for pediatric DTC remains under debate. The major controversial factors are the impact of extensive operations on recurrence and potential risks. Those who favor TT claim that this procedure is associated 
TABLE 9: Subanalysis of clinicopathological characteristics of patients with tumor size of 2 to $4 \mathrm{~cm}$.

\begin{tabular}{|c|c|c|c|c|}
\hline & $<20$ years $(n=47)$ & $20-29$ years $(n=187)$ & $30-39$ years $(n=367)$ & $p$ value \\
\hline Age (years) & $15.6 \pm 3.7$ & $25.9 \pm 2.6$ & $34.3 \pm 2.8$ & $<0.001$ \\
\hline Male : female & $1: 4.9$ & $1: 5.9$ & $1: 4.2$ & 0.374 \\
\hline Male & $8(17.0 \%)$ & $27(14.4 \%)$ & $70(19.1 \%)$ & \\
\hline Female & $39(83.0 \%)$ & $160(85.6 \%)$ & $297(80.9 \%)$ & \\
\hline Tumor size $(\mathrm{cm})$ & $2.8 \pm 0.7$ & $2.7 \pm 0.6$ & $2.6 \pm 0.6$ & 0.321 \\
\hline Type of carcinoma & & & & 0.859 \\
\hline PTC & $45(95.7 \%)$ & $178(95.2 \%)$ & $352(95.9 \%)$ & \\
\hline FTC & $2(4.3 \%)$ & $9(4.8 \%)$ & $15(4.1 \%)$ & \\
\hline Multifocality & $15(31.9 \%)$ & $42(22.5 \%)$ & $98(26.7 \%)$ & 0.385 \\
\hline Bilaterality & $13(27.7 \%)$ & $30(16.0 \%)$ & $73(19.9 \%)$ & 0.231 \\
\hline ETE & $24(51.1 \%)$ & $92(49.2 \%)$ & $192(52.3 \%)$ & 0.572 \\
\hline T stage & & & & 0.357 \\
\hline $\mathrm{T} 2^{\circ}$ & $20(42.6 \%)$ & $93(49.7 \%)$ & $172(46.9 \%)$ & \\
\hline $\mathrm{T} 3$ & $23(48.9 \%)$ & $85(45.5 \%)$ & $175(47.7 \%)$ & \\
\hline $\mathrm{T} 4$ & $4(8.5 \%)$ & $9(4.8 \%)$ & $20(5.4 \%)$ & \\
\hline $\mathrm{N}$ stage & & & & 0.006 \\
\hline No & $10(21.3 \%)$ & $67(35.8 \%)$ & $114(31.1 \%)$ & \\
\hline N1a & $14(29.8 \%)$ & $62(33.2 \%)$ & $154(42.0 \%)$ & \\
\hline N1b & $23(48.9 \%)$ & $58(31.0 \%)$ & $99(26.9 \%)$ & \\
\hline$M$ stage & & & & 0.260 \\
\hline M1 & $2(4.3 \%)$ & $0(0 \%)$ & $4(1.1 \%)$ & \\
\hline Recurrence & $12(25.5 \%)$ & $31(16.6 \%)$ & $35(9.5 \%)$ & 0.001 \\
\hline
\end{tabular}

Data are expressed as patient's number (\%) or mean \pm SD. A statistically significant difference was defined as $p<0.05$. PTC, papillary thyroid carcinoma; FTC, follicular thyroid carcinoma; ETE, extrathyroidal extension; T, tumor; N, node; $M$, metastasis.

TABLE 10: Univariate and multivariate analyses of DFS in three different age groups with tumor size of 2 to $4 \mathrm{~cm}$.

\begin{tabular}{lcccc}
\hline & \multicolumn{2}{c}{ Univariate } & \multicolumn{2}{c}{ Multivariate } \\
& HR $(95 \% \mathrm{CI})$ & $p$ & HR $(95 \% \mathrm{CI})$ & $p$ \\
value & value \\
\hline $\begin{array}{l}\text { Age (years) } \\
<20\end{array}$ & Ref. & & Ref. & \\
$20-29$ & 0.514 & 0.051 & 0.554 & 0.085 \\
& $(0.264-1.002)$ & & $(0.283-1.085)$ & \\
$30-39$ & 0.292 & & 0.305 & $<0.001$ \\
& $(0.151-0.563)$ & $<0.001$ & $(0.158-0.588)$ & \\
Bilaterality & 1.770 & & 1.758 & 0.029 \\
N stage & $(1.072-2.922)$ & 0.026 & $(1.061-2.913)$ & \\
N0 & Ref. & - & & \\
N1a & 1.468 & 0.198 & & \\
& $(0.818-2.634)$ & & & \\
N1b & 2.117 & 0.012 & & \\
& $(1.178-3.805)$ & & & \\
\hline
\end{tabular}

Data are expressed as hazard ratio (HR) and $95 \%$ confidence interval (CI). A statistically significant difference was defined as $p<0.05$. N, node.

with improved DFS without significant complications if performed by experienced professionals. Handkiewicz et al. concluded that TT was able to remove all malignant tissue, decrease recurrence risk, and improve patient outcomes [31]. In contrast, those who favor conservative treatment claim that the less aggressive approach is associated with comparable surgical outcomes in selected patients and is considerably safer than TT. Gulcelik et al. advocated less aggressive treatment to decrease the risk of surgical complications [44]. Due to the low incidence, slow progression, and need for long-term follow-up to identify

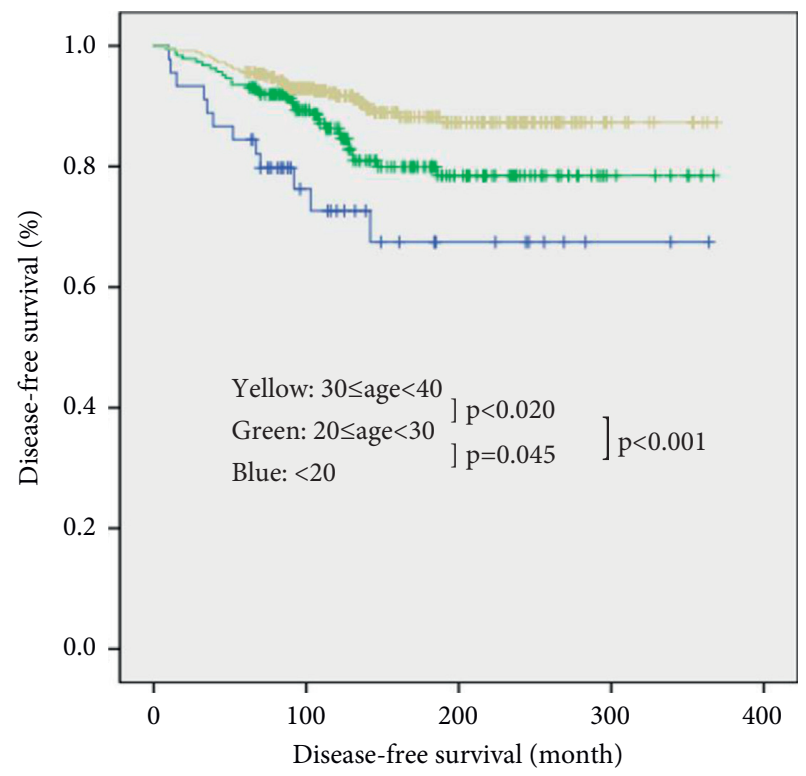

Figure 3: Disease-free survival curves of three groups with tumor size of 2 to $4 \mathrm{~cm}(\log$ rank; $<20$ years versus $20-29$ years, $p=0.045$; $<20$ years versus $30-39$ years, $p<0.001 ; 20-29$ years versus $30-39$ years, $p=0.020$ ).

precise diagnosis in pediatric patients, the gold standard operative approach for pediatric DTC remains controversial.

A strength of this study is that all patients were treated and followed up with the same protocol comprising surgery, TSH suppression, RAI therapy, and use of imaging modalities by a multidisciplinary team. However, several limitations of the study should be addressed. First, the study 
design was retrospective in nature. Second, there may have been selection bias given that patient data were collected from a single tertiary institution and may not reflect the entire patient population. Third, of the study population, only 98 patients were in the pediatric group, which was significantly smaller than the other groups. Fourth, the mean follow-up period was relatively short (120.4 \pm 54.2 months). This follow-up time limited our ability to compare long-term surgical outcomes between the three different age groups. Finally, only six (6.4\%) pediatric patients were below 10 years of age, and the mean age of pediatric patients was 16.7 years. As such, this sample may not have been reflective of the entire pediatric population.

\section{Conclusions}

To the best of our knowledge, there is a paucity of studies comparing clinical presentation and surgical outcomes between pediatric and adult groups. This study demonstrated that pediatric patients presented with more aggressive features compared to adult patients. Further, the recurrence rate of DTC was higher in pediatric patients than in adult patients. Given that age was identified as an independent risk factor for DFS, our findings underscore the need for pediatric patients with DTC to be carefully treated from initial evaluation to surgery and postoperative care.

\section{Data Availability}

The data that support the findings of this study are available upon request from the corresponding author. The data are not publicly available due to privacy or ethical restrictions.

\section{Conflicts of Interest}

The authors declare that there are no conflicts of interest.

\section{Acknowledgments}

The authors would like to thank all nurses helping the operations who have contributed to this study.

\section{Supplementary Materials}

Table S1: baseline clinicopathological characteristics of the study patients. (Supplementary Materials)

\section{References}

[1] D. A. Siegel, J. King, E. Tai, N. Buchanan, U. A. Ajani, and J. J. P. Li, "Cancer incidence rates and trends among children and adolescents in the United States, 2001-2009," Pediatrics, vol. 134, no. 4, pp. e945-e955, 2014.

[2] L. B. Vergamini, A. L. Frazier, F. L. Abrantes, K. B. Ribeiro, and C. Rodriguez-Galindo, "Increase in the incidence of differentiated thyroid carcinoma in children, adolescents, and young adults: a population-based study," The Journal of Pediatrics, vol. 164, no. 6, pp. 1481-1485, 2014.

[3] A. R. Hogan, Y. Zhuge, E. A. Perez, L. G. Koniaris, J. I. Lew, and J. E. J. J. Sola, "Pediatric thyroid carcinoma: incidence and outcomes in 1753 patients," Journal of Surgical Research, vol. 156, no. 1, pp. 167-172, 2009.

[4] M. T. Parisi and D. Mankoff, Eds., Seminars in Nuclear Medicine, Elsevier, Amsterdam, Netherlands, 2007.

[5] R. Miller, J. J. C. Young, and B. Novakovic, "Childhood Cancer," Cancer, vol. 75, pp. 395-405, 1995.

[6] N. L. Shapiro and N. J. T. L. Bhattacharyya, "Population-based outcomes for pediatric thyroid carcinoma," The Laryngoscope, vol. 115, no. 2, pp. 337-340, 2005.

[7] S. Leboulleux, E. Baudin, D. W. Hartl, J.-P. Travagli, and M. Schlumberger, "Follicular cell-derived thyroid cancer in children," Hormone Research in Paediatrics, vol. 63, no. 3, pp. 145-151, 2005.

[8] E. Steliarova-Foucher, C. Stiller, E. Pukkala, B. Lacour, I. Plesko, and D. Parkin, "Thyroid cancer incidence and survival among European children and adolescents (1978-1997): report from the Automated Childhood Cancer Information System project," European Journal of Cancer, vol. 42, no. 13, pp. 2150-2169, 2006.

[9] S. Yamashita and V. Saenko, "Mechanisms of disease: molecular genetics of childhood thyroid cancers," Nature Reviews Endocrinology, vol. 3, no. 5, p. 422, 2007.

[10] K. Pazaitou-Panayiotou, A. Kaprara, M. Boudina et al., "Thyroid carcinoma in children and adolescents. Presentation, clinical course, and outcome of therapy in 23 children and adolescents in Northern Greece," Hormones, vol. 4, no. 4, p. 213, 2005.

[11] I. D. Hay, T. Gonzalez-Losada, M. S. Reinalda, J. A. Honetschlager, M. L. Richards, and G. B. Thompson, "Long-term outcome in 215 children and adolescents with papillary thyroid cancer treated during 1940 through 2008," World Journal of Surgery, vol. 34, no. 6, pp. 1192-1202, 2010.

[12] G. L. Francis, S. G. Waguespack, A. J. Bauer et al., "Management guidelines for children with thyroid nodules and differentiated thyroid cancer: the American Thyroid Association guidelines task force on pediatric thyroid cancer," Thyroid, vol. 25, no. 7, pp. 716-759, 2015.

[13] A. M. Samuel and S. M. Sharma, "Differentiated thyroid carcinomas in children and adolescents," Cancer, vol. 67, no. 8, pp. 2186-2190, 1991.

[14] X.-C. Wu, V. W. Chen, B. Steele et al., "Cancer incidence in adolescents and young adults in the United States, 1992-1997," Journal of Adolescent Health, vol. 32, no. 6, pp. 405-415, 2003.

[15] B. R. Haugen, E. K. Alexander, K. C. Bible et al., "2015 American Thyroid Association management guidelines for adult patients with thyroid nodules and differentiated thyroid cancer: the American Thyroid Association guidelines task force on thyroid nodules and differentiated thyroid cancer," Thyroid, vol. 26, no. 1, pp. 1-133, 2016.

[16] K. Pazaitou-Panayiotou, P. K. Iliadou, S. Mandanas et al., "Papillary thyroid carcinomas in patients under 21 years of age: clinical and histologic characteristics of tumors $\leq 10 \mathrm{~mm}$," The Journal of Pediatrics, vol. 166, no. 2, pp. 451-456, 2015.

[17] R. K. Orosco, T. Hussain, K. T. Brumund, D. K. Oh, D. C. Chang, and M. Bouvet, "Analysis of age and disease status as predictors of thyroid cancer-specific mortality using the surveillance," Epidemiology, and End Results Database, vol. 25, no. 1, pp. 125-132, 2015.

[18] A. S. Alzahrani, D. Alkhafaji, M. Tuli, H. Al-Hindi, and B. B. Sadiq, "Comparison of differentiated thyroid cancer in children and adolescents ( $\leq 20$ years) with young adults," Clinical Endocrinology, vol. 84, no. 4, pp. 571-577, 2016. 
[19] S. S. Kim, S.-J. Kim, I. J. Kim, B. H. Kim, Y. K. Jeon, and Y. -K. Kim, "Comparison of clinical outcomes in differentiated thyroid carcinoma between children and young adult patients," Clinical Nuclear Medicine, vol. 37, no. 9, pp. 850-853, 2012.

[20] C. A. Dinauer, C. Breuer, and S. A. Rivkees, "Differentiated thyroid cancer in children: diagnosis and management," Current Opinion in Oncology, vol. 20, no. 1, pp. 59-65, 2008.

[21] I. Halac and D. Zimmerman, "Thyroid nodules and cancers in children," Endocrinology and Metabolism Clinics of North America, vol. 34, no. 3, pp. 725-744, 2005.

[22] Y.-M. Lee, C.-Y. Lo, K.-Y. Lam, K.-Y. Wan, and P. K. Tam, "Well-differentiated thyroid carcinoma in Hong Kong Chinese patients under 21 years of age: a 35-year experience," Journal of the American College of Surgeons, vol. 194, no. 6, pp. 711-716, 2002.

[23] F. Borson-Chazot, S. Causeret, J.-C. Lifante, M. Augros, N. Berger, and J.-L. Peix, "Predictive factors for recurrence from a series of 74 children and adolescents with differentiated thyroid cancer," World Journal of Surgery, vol. 28, no. 11, pp. 1088-1092, 2004.

[24] K. Segal, J. Shvero, Y. Stern, S. Mechlis, and R. Feinmesser, "Surgery of thyroid cancer in children and adolescents," Head and Neck, vol. 20, no. 4, pp. 293-297, 1998.

[25] J. K. Harness, N. W. Thompson, M. K. McLeod, J. L. Pasieka, and A. Fukuuchi, "Differentiated thyroid carcinoma in children and adolescents," World Journal of Surgery, vol. 16, no. 4, pp. 547-553, 1992.

[26] J. Farahati, C. Reiners, and E. P Demidchik, "Is the UICC/ AJCC classification of primary tumor in childhood thyroid carcinoma valid?" The Journal of Nuclear Medicine, vol. 40, no. 12, p. 2125, 1999.

[27] L. Lazar, Y. Lebenthal, A. Steinmetz, M. Yackobovitch-Gavan, and M. Philip, "Differentiated thyroid carcinoma in pediatric patients: comparison of presentation and course between prepubertal children and adolescents," The Journal of Pediatrics, vol. 154, no. 5, pp. 708-714, 2009.

[28] M. P. La Quaglia, T. Black, G. W. Holcomb III et al., "Differentiated thyroid cancer: clinical characteristics, treatment, and outcome in patients under 21 years of age who present with distant metastases. A report from the surgical discipline committee of the children's cancer group," Journal of Pediatric Surgery, vol. 35, no. 6, pp. 955-960, 2000.

[29] M. P. La Quaglia, M. T. Corbally, G. Heller, P. R. Exelby, and M. F. Brennan, "Recurrence and morbidity in differentiated thyroid carcinoma in children," Surgery, vol. 104, no. 6, pp. 1149-1156, 1988.

[30] C. A. Welch Dinauer, M. Tuttle, D. K. Robie et al., "Clinical features associated with metastasis and recurrence of differentiated thyroid cancer in children, adolescents and young adults," Clinical Endocrinology, vol. 49, no. 5, pp. 619-628, 1998.

[31] D. Handkiewicz-Junak, J. Wloch, J. Roskosz et al., "Total thyroidectomy and adjuvant radioiodine treatment independently decrease locoregional recurrence risk in childhood and adolescent differentiated thyroid cancer," The Journal of Nuclear Medicine, vol. 48, no. 6, pp. 879-888, 2007.

[32] B. Jarząb, D. H. Junak, J. Włoch et al., "Multivariate analysis of prognostic factors for differentiated thyroid carcinoma in children," European Journal of Nuclear Medicine and Molecular Imaging, vol. 27, no. 7, pp. 833-841, 2000.

[33] A. S. Fassina, M. Rupolo, M. R. Pelizzo, and D. Casara, "Thyroid cancer in children and adolescents," Tumori Journal, vol. 80, no. 4, pp. 257-262, 1994.
[34] A. Popovtzer, T. Shpitzer, G. Bahar, R. Feinmesser, and K. Segal, "Thyroid cancer in children: management and outcome experience of a referral center," OtolaryngologyHead and Neck Surgery, vol. 135, no. 4, pp. 581-584, 2006.

[35] K. Viswanathan, T. C. Gierlowski, and A. B Schneider, "Childhood thyroid cancer: characteristics and long-term outcome in children irradiated for benign conditions of the head and neck," Archives of Pediatrics and Adolescent Medicine, vol. 148, no. 3, pp. 260-265, 1994.

[36] N. Wada, K. Sugino, T. Mimura et al., "Pediatric differentiated thyroid carcinoma in stage I: risk factor analysis for disease free survival," BMC Cancer, vol. 9, no. 1, p. 306, 2009.

[37] B. A. Palmer, A. E. Zarroug, R. N. Poley, J. P. Kollars, and C. R. Moir, "Papillary thyroid carcinoma in children: risk factors and complications of disease recurrence," Journal of Pediatric Surgery, vol. 40, no. 8, pp. 1284-1288, 2005.

[38] I. Bongarzone, L. Fugazzola, P. Vigneri et al., "Age-related activation of the tyrosine kinase receptor protooncogenes RET and NTRK1 in papillary thyroid carcinoma," The Journal of Clinical Endocrinology and Metabolism, vol. 81, no. 5, pp. 2006-2009, 1996.

[39] Y. E. Nikiforov, J. M. Rowland, K. E. Bove, H. MonforteMunoz, and J. A. Fagin, "Distinct pattern of ret oncogene rearrangements in morphological variants of radiation-induced and sporadic thyroid papillary carcinomas in children," Cancer Research, vol. 57, no. 9, pp. 1690-1694, 1997.

[40] J. Lima, V. Trovisco, P. Soares et al., "BRAF mutations are not a major event in post-Chernobyl childhood thyroid carcinomas," The Journal of Clinical Endocrinology and Metabolism, vol. 89, no. 9, pp. 4267-4271, 2004.

[41] M. D. Ringel, J. Anderson, S. L. Souza et al., "Expression of the sodium iodide symporter and thyroglobulin genes are reduced in papillary thyroid cancer," Modern Pathology, vol. 14, no. 4, p. 289, 2001.

[42] A. Patel, S. Jhiang, S. Dogra et al., "Differentiated thyroid carcinoma that express sodium-iodide symporter have a lower risk of recurrence for children and adolescents," Pediatric Research, vol. 52, no. 5, pp. 737-744, 2002.

[43] J.-J. Min, J.-K. Chung, Y. Lee et al., "Relationship between expression of the sodium/iodide symporter and 131 I uptake in recurrent lesions of differentiated thyroid carcinoma," European Journal of Nuclear Medicine and Molecular Imaging, vol. 28, no. 5, pp. 639-645, 2001.

[44] M. A. Gulcelik, B. Kuru, H. Dincer et al., "Complications of completion versus total thyroidectomy," Asian Pacific Journal of Cancer Prevention, vol. 13, no. 10, pp. 5225-5228, 2012. 